\title{
Music Video Viewers' Preference Evaluation Criteria and Their Characteristics
}

\author{
Maiko Kamata and Michiaki Yasumura \\ Graduate School of Media and Governance, Keio University. \\ 5322 Endo, Fujisawa-shi, Kanagawa-ken, Japan \\ \{kamata, yasumura\} @sfc.keio.ac.jp
}

\begin{abstract}
This study investigated music video viewers' characteristics and their preference evaluation criteria. We had detailed interviews based on the evaluation grid method with ten participants. All participants watch music videos frequently. Our participants could be divided into following two types: (1) Singer-based type viewers: they emphasized the importance of the singer(s) singing the song in their preference evaluation criteria. (2) Image-based type viewers: they insisted that the images were the high-priority parameters in their preference evaluation. It is noteworthy that their preference criteria and viewing style were affected by whether they prefer Japanese or English songs.
\end{abstract}

Keywords: music video, viewer, preference evaluation, detailed interviews.

\section{Introduction}

Music video has been supporting today's music industry in terms of promotion and entertainment. Today, music video is a well-known media and is available on television, DVD, and the internet. Viewers with experienced-eyes naturally demand for more attractive music videos. Thus, it is crucial for music video designers to create music videos that meet viewers' expectations. Under the current circumstance, a study that approaches the insight of viewers surely offers the key to a development of entertainable music video making methodology.

In this study, we carried out a case study interview with frequent music video viewers and investigated relationships between their preference evaluation criteria and participants' characteristics. We believe that this study provides an opportunity to deepen our understandings of viewers. Moreover, we also aim to develop music video making methodology. Our discussion will help music video designers to carry out their work with their target viewers in mind.

\section{Previous Work}

Our previous work discussed characteristics of viewers' favorite music videos by using the k-means clustering analysis. As a result, we found that there were three types of viewers' favorite music videos. The results indicated that the primary reason 
that viewers favored the music videos were: (1) auditory-leading type: they liked music and singer; (2) visual-leading type: they were amazed by the imaging technique; (3) synergic type: they got favorable impressions overall. This result suggests the important factors to be included in attractive music videos [1].

However, we have not revealed who prefer which type of music video. In other words, it is still not clear that what kind of personality appreciates what kinds of music videos. Against this backdrop, this paper is intended as an investigation of this relationship between viewers' personality and their favorite music videos.

\section{Interview Methods}

We had detailed interviews based on the evaluation grid method with ten undergraduate students. The evaluation grid method is a detailed interview method that is used for clarifying participants' concrete evaluation criteria towards a certain object [2].

We first asked participants to write down titles of their favorite music videos on cards. Next, participants were asked to line up the cards from their most favorite to least favorite on a table. Then, we pointed pairs of cards and asked them why they prefer one over another. These procedures enabled participants to express their specific evaluation criteria easily. Each session took forty to fifty minutes to complete.

Table 1. Participants Details. The participants in this interview were all Japanese students from our University. Six males and four females, age 19 to 23 (mean: 21.4, Standard Deviation: 1.29). They all watch music videos more than one time per week. We also asked them their favorite music category (Japanese or English or both) and oversea experience.

\begin{tabular}{cccccc}
\hline ID & AGE & SEX & $\begin{array}{c}\text { FREQUENCY } \\
\text { they watch }\end{array}$ & MUSIC they like & $\begin{array}{c}\text { OVERSEA experience } \\
\text { (6month+) }\end{array}$ \\
\hline A & 21 & $\mathrm{~F}$ & $1-2 /$ per week & English & Yes \\
B & 20 & $\mathrm{~F}$ & $2-3 /$ per week & English & No \\
$\mathbf{C}$ & 22 & $\mathrm{M}$ & $1-2 /$ per week & Japanese & Yes \\
D & 23 & $\mathrm{M}$ & $2-3 /$ per week & Japanese & No \\
$\mathbf{E}$ & 22 & $\mathrm{M}$ & $2-3 /$ per week & Mainly Japanese & No \\
$\mathbf{F}$ & 22 & $\mathrm{~F}$ & $2-3 /$ per week & Mainly English & Yes \\
$\mathbf{G}$ & 19 & $\mathrm{~F}$ & $1-2 /$ per week & English & Yes \\
$\mathbf{H}$ & 21 & $\mathrm{M}$ & $2-3 /$ per week & Japanese & No \\
I & 22 & $\mathrm{M}$ & $2-3 /$ per week & Japanese & No \\
J & 23 & $\mathrm{M}$ & $2-3 /$ per week & English & Yes \\
\hline
\end{tabular}

\section{Results of the Interview}

In this survey, the most fundamental preference criterion for our participants was either the singer or the image of music video. Although most of them value both criteria, they give great importance on one. Here, we divided participants into two types in order to investigate viewers' characteristics closely according to their preference criteria. 


\section{(1) Singer-Based Type}

The ultimate evaluation criterion for the participant A, C, D, H and I were the singer(s) who sang the song. In fact, almost all of their favorite music videos were of their favorite singer(s). Their primary purpose of watching music videos is to expose their favorite singers.

\section{(2) Image-Based Type}

We categorized participant B, E, F, G, and J as the image-based type. It is notable that most of the image-based viewers were with experience of residing outside of Japan over six months. One exception, B, aspired to go abroad and now she is currently preparing for her staying in an English-spoken country. Overall, the image-based type viewers were interested in music in general and invested a good deal of time to experience various styles of music videos. They often contact media that provides to a broad range of music videos such as the internet radios and music-only TV programs.

It is worth arguing that there were radical differences between the singer-based and image-based types on the following four points:

(a) Music: the singer-based viewers tend to prefer Japanese pop songs whereas the image-based viewers were passionate listeners of the English songs.

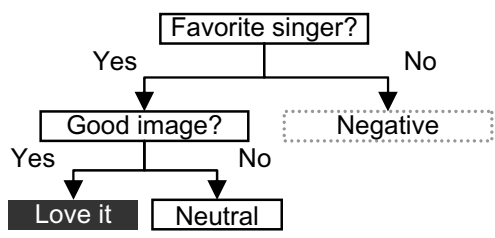

Fig. 1. Singer-based Type Preference Evaluation

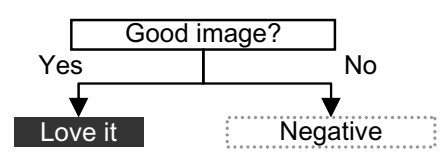

Fig. 2. Image-based Type Preference Evaluation

Table 2. Cross-Classification of Preference on Music by Types. Fisher's exact significance probability was $\mathrm{p}=0.103(>.10)$ and did not recognise a statistical association between their preference on music and evaluation type. Although we could not confirm the association statistically, we can read a certain tendency from this table.

\begin{tabular}{cccc}
\hline & $\begin{array}{c}\text { Singer- } \\
\text { Based }\end{array}$ & $\begin{array}{c}\text { Image- } \\
\text { Based }\end{array}$ & Total \\
\hline J-Pop & 4 & 1 & 5 \\
English & 1 & 4 & 5 \\
Total & 5 & 5 & 10 \\
\hline
\end{tabular}

(b) Purpose: the singer-based viewers watch music videos because they consider music videos as a tool to admire their favorite singers. On the other hand, the main purposes for the image-based viewers were to enrich their listening experience or gathering information. This fact gave us a clue to explain why the singer-based preferred the audio-leading type and the image-based preferred the visual-leading type music videos.

(c) Media: the singer-based viewers first encounter shortened or edited music videos by hit charts TV programs. When they are motivated to see more, they purchase 
music video DVD or go to the singer's website to be satisfied. On the other, the image-based only watch full-length music videos by the internet radios and all-music TV channels.

(d) Viewing experience: the singer-based viewers had narrow experience and dedicated their time for their favorite singers. Meanwhile, the image-based had vast experience and found pleasure in getting acquainted with attractive images.

One interpretation of these clear contrasts is that viewers' preference on music (i.e. Japanese pop or English) affects on their viewing style. People prefer Japanese pop naturally access Japanese media and get used to it which usually offers edited versions of music videos. In contrast, participants who favored English songs exposed to western-based media which brings full-length viewing experience. This is probably the reason for good agreement between viewers' preference on music and preference criteria and their viewing styles.

\section{Conclusion}

In this paper, we explored relationships between viewers' personality and their preference criteria of music videos. We found that the most significant evaluation criterion was either the singer or the image of the music video. We also recognized remarkable differences between viewers of the singer-based and the image-based type. It seems reasonable to assume that viewers' viewing style and preference evaluation were closely related to their preference of music.

Taken together, we suggest music video designers to identify their main viewers' type and concentrate on fulfilling their expectation. In addition, viewers' mediacultural background deserves careful attention because it is a key factor that cultivates viewers' preference evaluation.

\section{Acknowledgements}

Authors would like to thank all of our participants and Professor Makoto Arisawa of Content Engineering Lab in Keio University for his support of this study.

\section{References}

1. Kamata, M., Furukawa, K.: Three Types of Viewers' Favorite Music Videos. In: Proc. of the International Conference on Advances in Computer Entertainment Technology 2007, Salzburg, Austria, pp. 196-199 (2007)

2. Sanui, J., Inui, M.: Phenomenological Approach to the Evaluation of Places: A study on the construct system associated with place evaluation. Journal of architecture, planning and environmental engineering. Transactions of AIJ 367, 15-22 (1986) 